Conclusions: Psychological stress was not increased in the phase of arthralgia, raised at the time of diagnoses and decreased thereafter. This temporal-relationship, and the lack of association with inflammation in arthralgia, argue against psychological stress having a significant contribution to inflammatory arthritis development.

Disclosure of Interest: None declared

DOI: 10.1136/annrheumdis-2018-eular.3278

\section{FRI0093 DON'T MISS THE DEPRESSION! COMORBIDITIES IN PATIENTS WITH RHEUMATOID ARTHRITIS AND THEIR IMPACT ON PATIENT-REPORTED OUTCOMES: RESULTS OF CLAIMS DATA LINKED TO A QUESTIONNAIRE SURVEY}

K. Albrecht ${ }^{1}$, A. Luque Ramos ${ }^{2}$, J. Callhoff ${ }^{1}$, I. Redeker ${ }^{1}$, F. Hoffmann ${ }^{2}$, A. Zink ${ }^{1}$. ${ }^{1}$ Epidemiology, German Rheumatism Research Center, Berlin; ${ }^{2}$ Health Services Research, Carl von Ossietzky University, Oldenburg, Germany

Background: Comorbidities are increasingly acknowledged as important clinical manifestation in patients with rheumatoid arthritis (RA)

Objectives: To investigate the prevalence of comorbidities in RA and their association with patient-reported outcomes.

Methods: Data of 96921 persons with RA and 484605 age- and sex-matched controls of a German statutory health fund were studied on the presence of selected comorbidities in 2015. Diagnoses and therapies were assigned to the provider (general practitioner, rheumatologist or another specialist). A selfreported questionnaire, comprising joint counts (TJC, SJC), functional status $(\mathrm{FFbH})$, impact of the disease (RAID) and well-being (WHO-5) was sent to a random sample of 6195 persons with RA of whom 3184 responded. For respondents who confirmed their RA $(n=2,535)$, the association between comorbidities and patient-reported outcomes were analysed by multivariable linear regression analyses.

Results: Compared to controls, persons with RA (mean age 63 years, $80 \%$ female) had higher prevalences of all comorbidities, the most common were depression and osteoporosis besides cardiovascular risk factors (table 1). The diagnosis of depression was provided in $50 \%$ of cases by general practitioners, in $13 \%$ by rheumatologists and in $48 \%$ by other specialists while the diagnosis of osteoporosis was made in $76 \%$ by general practitioners, in $48 \%$ by rheumatologists and in $46 \%$ by other specialists. Among the survey respondents, increasing numbers of comorbidities were associated with worse TJC, SJC, function and WHO- 5 values. Depression, obesity and osteoporosis had the highest impact on functional status and TJCs. The percentage of patients in rheumatologic care decreased from $73 \%$ with $0-1$ comorbidity to $62 \%$ with $\geq 8$ comorbidities (ageadjusted).

Abstract FRI0093 - Table 1. Prevalence of selected comorbidities in cases and controls

\begin{tabular}{lcc}
\hline & $\begin{array}{c}\text { RA patients } \mathrm{n}=96921 \\
\%(95 \% \mathrm{Cl})\end{array}$ & $\begin{array}{c}\text { Controls } \mathrm{n}=484605 \\
\%(95 \% \mathrm{Cl})\end{array}$ \\
\hline $\begin{array}{l}\text { Cardiovascular risk factors } \\
\text { Hypertension }\end{array}$ & $61.8(61.5-62.1)$ & $48.0(47.8-48.1)$ \\
Hyperlipidemia & $39.4(39.1-39.7)$ & $32.4(32.2-32.5)$ \\
Obesity & $17.7(17.5-18.0)$ & $12.3(12.2-12.3)$ \\
Comorbid disorders & & \\
Depression & $31.4(31.1-31.7)$ & $20.4(20.3-20.5)$ \\
Osteoporosis & $25.7(25.4-26.0)$ & $9.7(9.6-9.8)$ \\
Diabetes & $21.5(21.2-21.7)$ & $15.3(15.2-15.4)$ \\
Cardiac arrhythmia & $18.8(18.5-19.0)$ & $13.2(13.1-13.3)$ \\
Hypothyroidism & $17.9(17.6-18.1)$ & $12.8(12.7-12.9)$ \\
Coronary heart disease & $15.2(15.0-15.4)$ & $9.6(9.5-9.7)$ \\
Liver disease & $13.8(13.6-14.0)$ & $9.1(9.0-9.1)$ \\
Vascular diseases & $12.9(12.7-13.1)$ & $8.5(8.4-8.6)$ \\
Asthma & $12.3(12.1-12.5)$ & $7.4(7.3-7.4)$ \\
COPD & $11.3(11.0-11.4)$ & $6.6(6.5-6.6)$ \\
\hline
\end{tabular}

Conclusions: Osteoporosis and depression are amongst the most common disorders in persons with RA. While osteoporosis is usually taken into account by the rheumatologist, more attention should be paid to depression as both disorders strongly affect patient-reported outcomes.

Acknowledgements: This study was funded by the German Federal Ministry of Education and Research (01EC1405).

Disclosure of Interest: None declared

DOI: 10.1136/annrheumdis-2018-eular.2399

\section{FRI0094}

DOES SUBCLINICAL INFLAMMATION EXPLAIN JOINT PAIN IN PATIENTS WITH ARTHRALGIA SUSPICIOUS FOR PROGRESSION TO RHEUMATOID ARTHRITIS? RESULTS OF A CROSS-SECTIONAL MRI-STUDY

L.E. Burgers, R.M. ten Brinck, D.M. Boeters, A.H.M. van der Helm-van Mil. Rheumatology, Leiden University Medical Centre, Leiden, Netherlands

Background: The development of Rheumatoid Arthritis (RA) is often preceded by a symptomatic phase of arthralgia. The etiology of symptoms in this phase is unclear.

Objectives: Since subclinical joint inflammation is expected to be causally related to pain, we aimed to determine associations between subclinical MRI-detected inflammation and pain in patients with arthralgia suspicious for progression to RA. Methods: Unilateral MRIs of the wrist, MCP(2-5)- and MTP(1-5)-joints of 325 patients who fulfilled the EULAR definition of arthralgia suspicious for progression to RA were made and scored by two readers on subclinical inflammation (synovitis, bone marrow oedema (BME) and tenosynovitis). Associations between MRIdetected inflammation and overall pain severity at patient level (measured using the visual analogue scale (VAS)), and local tenderness at joint palpation, were studied in all patients, in ACPA-positive and ACPA-negative patients separately, and in the subgroup of patients that progressed to inflammatory arthritis.

Results: At patient level, synovitis $(\beta=0.10, p=0.048)$ and tenosynovitis $(\beta=0.11$ $p=0.026)$ associated with the VAS-pain. Of the 1620 imaged joints, $447(28 \%)$ were tender. Subclinical inflammation was present in $32 \%$ of tender joints and in $25 \%$ of non-tender joints. MRI-detected synovitis associated independently with joint tenderness (OR 1.74, $\mathrm{p}<0.001$ ). In ACPA-negative patients synovitis associated independently with joint tenderness (OR 1.96, $\mathrm{p}<0.001$ ), while BME was independently associated with joint tenderness in ACPA-positive patients (OR $2.39, p=0.005)$. Sensitivity analyses in patients who developed arthritis during follow-up ( $n=61$ ) revealed similar associations.

Conclusions: In patients with arthralgia suspicious for progression to RA, joint tenderness and pain are associated with MRI-detected subclinical inflammation. The association is incomplete, indicating that subclinical inflammation is not the sole explanation of the arthralgia.

Disclosure of Interest: None declared

DOI: 10.1136/annrheumdis-2018-eular.3294

\section{FRI0095 ANTI-TNFA VERSUS RITUXIMAB IN REFRACTORY PERIPHERAL ULCERATIVE KERATITIS ASSOCIATED TO RHEUMATIC DISEASES. MULTICENTER STUDY OF 24 PATIENTS}

L.C. Domínguez Casas ${ }^{1}$, V. Calvo-Río ${ }^{1}$, O. Maíz-Alonso ${ }^{2}$, A. Blanco ${ }^{3}$, E. Beltran ${ }^{4}$, L. Martinez Acosta ${ }^{5}$, M.C. Alvarez de Buergo ${ }^{6}$, E. Rubio-Romero ${ }^{7}$, D. Díaz-Valle ${ }^{8}$, R. López-González ${ }^{9}$, A. García- Aparicio ${ }^{10}$, A. Juan Mas ${ }^{11}$, E. Pons ${ }^{1}$, R. DemetrioPablo ${ }^{12}$, N. Vegas-Revenga ${ }^{1}$, R. Blanco ${ }^{1}$, M. Gonzalez-Gay ${ }^{1} .{ }^{1}$ Rheumatology, HUMV, Santander, ${ }^{2}$ Rheumatology, ${ }^{3}$ Ophtalmology, Hospital Universitario Donostia, San Sebastian; ${ }^{4}$ Rheumatology, Hospital General Universitario de Valencia; ${ }^{5}$ Ophtalmology, Hospital Peset, Valencia; ${ }^{6}$ Rheumatology, Hospital Río Carrión, Palencia; ${ }^{7}$ Ophtalmology, Hospital Universitario Virgen del Rocío, Sevilla; ${ }^{8}$ Ophtalmology, Hospital Clínico San Carlos, Madrid; ${ }^{9}$ Rheumatology, Complejo hospitalario de Zamora, Zamora; ${ }^{10}$ Rheumatology, Hospital de Toledo, Toledo;

${ }^{11}$ Rheumatology, Hospital Son Laàtzer, Palma de Mallorca; ${ }^{12}$ Ophtalmology, HUMV, Santander, Spain

Background: This study shows that treatment with biologic drugs, including antTNF drugs, in NION associated to IMIDs, refractory to conventional treatment, seems to be effective. These results must be confirmed in prospective and randomised trials.

Objectives: Our aim was to compare anti-TNF $\alpha$ vs Rituximab (RTX) in refractory PUK.

Methods: Multicenter study of 24 patients with PUK. All of them presented inadequate response to corticosteroids and at least 1 systemic traditional immunosuppressive drug.

Anti-TNF $\alpha$ were used in 17 patients: Adalimumab ( $\mathrm{n}=9) 40 \mathrm{mg} / \mathrm{sc}$ every 1-2 weeks, infliximab (IFX) ( $\mathrm{n}=7) 3-5 \mathrm{mg} / \mathrm{kg}$ iv $/ 4-6$ weeks, etanercept $(n=1) 50 \mathrm{mg} /$ week. RTX was used in 7 patients $1-2 \mathrm{~g}$ i.v. every 6 or 12 months.

The main outcomes were Best Corrected Visual Acuity (BCVA), signs of inflammation (scleritis and episcleritis), progression to corneal thinning, central keratolysis and ocular perforation. 
Abstract FRI0095 - Table 1

\begin{tabular}{|c|c|c|c|}
\hline & $\begin{array}{l}\text { anti-TNFa } \\
n=17\end{array}$ & $\begin{array}{l}\text { RTX } \\
n=7 \\
\end{array}$ & $\overline{P P}$ \\
\hline \multicolumn{4}{|l|}{ General features } \\
\hline $\operatorname{Sex}(\varepsilon / \hat{q})$ & $4 / 2$ & $13 / 5$ & 0.79 \\
\hline Mean age (vears) & $59.1 \pm 18.3$ & $54.28 \pm 10.7$ & 0.49 \\
\hline $\begin{array}{l}\text { Ocular bilateral } \\
\text { involvement = }\end{array}$ & 23.53 & 57.14 & 0.13 \\
\hline $\begin{array}{l}\text { Duration of underlying } \\
\text { diseases (days) }\end{array}$ & $183.06 \pm 18.3$ & $138.85 \pm 77.68$ & 0.59 \\
\hline \multicolumn{4}{|l|}{ Basal } \\
\hline $\mathrm{BCVA}^{\mathrm{x}}$ & $0.58 \pm 0.38$ & $0.56 \pm 0.34$ & 0.68 \\
\hline Peripheral thinnina $=$ & 18 & 9 & 0,77 \\
\hline Centralkeratolysis =8 & 4 & 1 & 0.59 \\
\hline Ocular perforation $=$ & 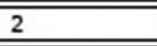 & 1 & 0.89 \\
\hline Scleritis $=$ & 3 & 8 & 0.001 \\
\hline Episcleritis = & 3 & 4 & 0.15 \\
\hline Uveitis = & 3 & 2 & 0.77 \\
\hline \multicolumn{4}{|l|}{ 1" month $^{\text {st }}$} \\
\hline $\mathrm{BCVA}^{8}$ & $0.67 \pm 0.31$ & $0.56 \pm 0.27$ & 0.67 \\
\hline Peripheral thinnina $=$ & 5 & 6 & 0.032 \\
\hline Centralkeratolysis $=^{*}$ & - & - & 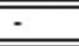 \\
\hline Ocular perforation = & - & - & - \\
\hline Scleritis $=$ & 1 & 1 & 0.54 \\
\hline Episcleritis $=$ & 1 & 0 & 0.45 \\
\hline Uveitis $=$ & 1 & 2 & 0.23 \\
\hline \multicolumn{4}{|l|}{$6^{\prime m}$ month } \\
\hline $\mathrm{BCVA}^{\mathrm{B}}$ & $0.7 \pm 0.25$ & $0.73 \pm 0.29$ & 0.67 \\
\hline Peripheral thinning $=$ & 9 & 3 & 0.14 \\
\hline Centralkeratolysis $=^{*}$ & 0 & 3 & 0.028 \\
\hline Ocular perforation $=$ & - & - & - \\
\hline Scleritis $=$ & - & - & - \\
\hline Episcleritis = & - & - & - \\
\hline Uveitis = & 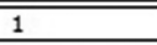 & 0 & 0.38 \\
\hline \multicolumn{4}{|l|}{ 1st year } \\
\hline $\mathrm{BCVA}^{\mathrm{x}}$ & $0.75 \pm 0.22$ & $0.70 \pm 0.24$ & 0.77 \\
\hline Peripheral thinning = & 7 & 3 & 0.25 \\
\hline Centralkeratolysis $=^{8}$ & 1 & 1 & 0.89 \\
\hline Ocular perforation = & 0 & 1 & 0.30 \\
\hline Scleritis $=$ & - & $=$ & - \\
\hline Episcleritis = & - & - & - \\
\hline Uveitis $=$ & 1 & 0 & 0.35 \\
\hline
\end{tabular}

Comparisons. were made between baseline and 1 st month, 6th month and 1 st year (STATISTICA, StatSoft Inc. Tulsa, Oklahoma, USA). Quantitative variables were expressed as mean $\pm S D$ or median [IQR], accordingly to its distribution. They were compared with the Student t or the Mann-Whitney U test respectively. Dichotomous variables were expressed as percentages and compared by the chisquare test.

Results: We studied 24 patients/32 affected eyes. The underlying diseases in the anti-TNF $\alpha$ group were Rheumatoid Arthritis $(R A)(n=14)$, Psoriatic Arthritis $(n=2)$ and Behçet Disease $(n=1)$; and in the RTX group: RA ( $n=5)$, granulomatous polyangiitis $(n=1)$ and microscopic polyangiitis $(n=1)$.

At baseline there were no significant differences between both groups in general features or in ocular involvement (table 1). Before biologic therapy they had received the following systemic drugs (anti-TNF $\alpha$ vs RTX) i.v. methylprednisolone ( 2 vs 4 ), doxycycline ( 7 vs 1 ), ascorbic acid ( 2 vs 0 ), MTX (11 vs 4), AZA (1 vs 2 ) and others (7 vs 3). In addition, 10 patients, in both groups, had required surgery: amniotic membrane $(n=5)$, penetrating keratoplasty $(n=2)$, conjunctival resection $(n=2)$, tissue adhesives $(n=2)$, conjunctival flap $(n=1)$ and lamellar keratoplasty $(n=1)$.

Once the treatment was initiated the ocular outcome was similar (table 1).

After a mean follow-up of $22.53 \pm 22.60$ (anti-TNF $\alpha$ ) and $22.28 \pm 8.28$ months with RTX the following severe side effects were observed: supraventricular tachycardia $(n=1)$ with $R T X$ and pulmonary tuberculosis $(n=1)$ with IFX.
Conclusions: In this study, anti-TNF $\alpha$ therapy and RTX were equally effective for the treatment of peripheral ulcerative keratitis associated to rheumatic diseases refractory to conventional treatment.

Disclosure of Interest: None declared

DOI: 10.1136/annrheumdis-2018-eular.2622

\section{FRI0096 IS SIDE EFFECTS AND TREATMENT RESPONSE TO METHOTREXATE ASSOCIATED TO COMORBIDITY IN EARLY RHEUMATOID ARTHRITIS}

K.L. Pedersen ${ }^{1}$, J. Hallas ${ }^{2}$, I.M.J. Hansen ${ }^{3}$, P. Ahlquist ${ }^{4}$, T. Ellingsen ${ }^{5} .{ }^{1}$ Hospital $^{\prime}$ Pharmacy of Funen, Odense University Hospital; ${ }^{2}$ Clinical Pharmacology and Pharmacy, Department of Public Health; ${ }^{3}$ Dept of Rheumatology, Odense University Hospital; ${ }^{4}$ Reumaclinic Funen, Reuamaclinic Funen; ${ }^{5}$ Rheumatology, Odense University Hospital, Odense, Denmark

Background: In Denmark approximately $0.7 \%$ (35.000) of the population is diagnosed with rheumatoid arthritis $(R A)$. RA is a risk factor in development of comorbidity, and comorbidities are not well managed in RA patients. In addition of being first line treatment of early RA, methotrexate (MTX) gives a 70\% reduction in cardiovascular disease caused mortalities, and if treatment exceeds a year, the general mortality risks are lowered by $60 \%$. Discontinuation of MTX is therefore a bad outcome for RA. It remains unclear whether side effects and treatment response to MTX is associated to comorbidity in early RA.

Objectives: To evaluate the association between comorbidity and persistence to MTX treatment and side effects for RA patients.

Methods: Patient files from three centres were evaluated retrospectively. Inclusion criteria were: diagnosis obtained according to $A C R /{ }^{E U L A R} 2010$ criteria for RA in the period 01/01/2010 to present, and MTX as first line of treatment. Medical records were reviewed for side effects, dose changes of MTX, formulation changes and persistence. Comorbidities and comedication was evaluated by usage of the Danish National Patient Registry (DNPR), and the Odense Pharmacoepidemiological Database (OPED). Comorbidities were scored according to the Charlson Comorbidity Index (CCl), and analysed by the cox proportional hazards model for discontinuation of MTX treatment and dose reduction.

Results: 501 patients were screened, 177 were eligible and analysed at baseline for disease characteristics, medication besides MTX and comorbidities in a 5 yea window before RA diagnosis baseline. The highest risk of MTX discontinuation was a CCl of 3-4, they had crude $4.18(95 \% \mathrm{Cl} 1.67-10.45)$ increased risk compared to the reference group (RA with no comorbidities). Risk of dosage reduction was highest at CCI 1-2: $1.38(95 \% \mathrm{Cl} 0.72-2.62)$. A CCl of 5 or higher gave a $-4.83 \mathrm{mg}(95 \% \mathrm{Cl}-10.24-0.59)$ adjusted difference in maximum weekly tolerable MTX dosage. Side effects occurred for $23.7 \%$. Most likely dosage causing side effect was $20 \mathrm{mg}$ (IQR 15-20 mg). Nausea occurred in 29\% and hepatic events $21 \%$.

Conclusions: Patients with $\mathrm{CCl}$ in the range of $3-4$ had an increased risk for discontinuing MTX treatment.

Disclosure of Interest: None declared

DOI: 10.1136/annrheumdis-2018-eular.2608

\section{FRI0097 EXPRESSION OF UNCOUPLING PROTEIN-1 IN SUBCUTANEOUS FAT REDUCES THE TOTAL CHOLESTEROL LEVEL AND CARDIOVASCULAR RISK IN FEMALE RA PATEINTS}

L.I. Lyngfelt, M.C. Erlandsson, M. Nadali, K.M. Andersson, S.T. Silfverswärd, R. Pullerits, M.I. Bokarewa. Department of Rheumatology and Inflammation Research, University of Gothenburg, Gothenburg, Sweden

Objectives: To improve understanding of fat-related molecular mechanisms behind the increased cardiovascular (CV) morbidity in patients with rheumatoid arthritis (RA).

Methods: Transcription of uncoupling protein 1 (UCP1) was measured in the subcutaneous fat tissue and serum levels of lipoproteins, adipokines, and inflammation markers in 185 middle-aged female patients (mean age 51 years) with RA and compared between the groups stratified by the total cholesterol (TC) levels and the body mass index (BMI). The risk of dying of CV disease within 5 years was calculated electronically using the strategy proposed by Pocock et al. ${ }^{1}$

Results: CVR was highest (risk score 27.76, 5 year CVR $0.67 \%$ ) in the patients combining high TC $(>5.1 \mathrm{mmol} / \mathrm{L})$ and high BMI $(>25 \mathrm{~kg} / \mathrm{m} 2)$, while those with low levels of TC and BMI had lowest CVR (risk score 10.82, CVR 0.11\%). CVR was significantly decreased if either $\mathrm{TC}\left(\mathrm{TC}^{\mathrm{lo}} \mathrm{BMI} \mathrm{l}^{\mathrm{hi}}\right)$ or $\mathrm{BMI}\left(\mathrm{TC}^{\text {hi }} \mathrm{BMI} \mathrm{I}^{\mathrm{lo}}\right)$ was low $\left(p=0.017\right.$ and $p=0.014$, respectively). With the exception of $\mathrm{TC}^{\mathrm{lo}} \mathrm{BM} \mathrm{l}^{\mathrm{lo}}$ group, these groups had no difference with respect to age, disease duration, inflammation defined by serum IL 6 and IL 1 , and disease activity measured by DAS28. $\mathrm{TC}^{\mathrm{lo}} \mathrm{BMl} \mathrm{I}^{\mathrm{hi}}$ patients had an overall increase in fat expression of UCP1 $(\mathrm{p}=0.047)$ that has the cholesterol lowering capacity and may explain low TC levels in this 